Reinders, H., Hacker, P. \& Lewis, M. 2004 'The language advisor's role: identifying and responding to needs'. Language Learning Journal 30: 30-35.

\title{
THE LANGUAGE ADVISOR'S ROLE: IDENTIFYING AND RESPONDING TO NEEDS
}

Written by Hayo Reinders, www.hayo.nl

\begin{abstract}
Tertiary institutions increasingly offer language advisory sessions for second language students and staff. Advisors help students to identify language and learning needs, they recommend resources and strategies, and they provide feedback and encouragement. Especially in the first few sessions, identifying and prioritising needs is arguably among the most important goals, but there are few guidelines for advisors on how to elicit information from students or how to respond to learners' self-reported needs. In fact, little is known about the processes through which advisors and students come to an agreed set of needs and solutions. This article reports a two-stage professional development project between an adviser and two other researchers. At the first stage the adviser recorded three initial sessions with one student. This was followed by a transcription and analysis of the sessions and discussion with the other two researchers. One of the main outcomes was that the advisor felt she had to be more directive. The second stage involved a session with a different student. Here the adviser's aim was to be more specific and guiding, while encouraging the student to initiate topics and ideas. The findings from the two stages are analysed and compared.
\end{abstract}

\section{Language advising}

In recent years language advisory services have been offered in more and more educational settings around the world. This may be due in part to an increased interest in fostering 
autonomous (language) learning, but practical (especially financial) reasons also play a role (Mozzon-McPherson \& Vismans 2001). Language advisory services are sometimes provided by language counsellors operating independently (as a service separated from other types of language support), but advisory services are also offered within Self-Access Centres (SACs) by self-access staff. In the university context these SACs often deal with large numbers of students who have little time to improve their language skills. In addition, opportunities for contact between lecturing and teaching staff and students are limited. Advisory sessions make more extensive and regular contact possible. This type of service need not take place in the Centre, however. Makin (1994), for example, reports on 'telesupport' through email, Hurd (2001) reports on advising in open and distance learning programmes, and Reinders discusses support offered through an electronic learning environment $(2002,2004 a)$. One thing that many advisory sessions have in common, though, is that participation tends to be voluntary and ad hoc; structured programmes are less common.

The voluntary aspect of many language advisory sessions can be problematic. Voller, Martyn and Pickard (1999) for example, report on a number of problems, including the fact that these sessions lack clear objectives and fail to provide learners with an opportunity to acquire appropriate study techniques. Fu (1999) highlights a common problem: 'A person will come for what the counsellor perceives is a substantial and interesting discussion or learning dialogue, and then the counsellor never sees that person again, therefore getting neither any feedback nor report on progress (or lack of it)' (p. 107).

This does not necessarily mean that the session has been fruitless. As Fu (ibidem) points out 'a seed may have been planted' (p. 107) but this is difficult to tell. So how can we know if a session has been successful? For an evaluation to be meaningful, goals and outcomes have to be clear and measurable. However, advisory sessions are mostly couched in terms such as 'the fostering of learner autonomy', 'raising awareness', or 'the promotion of strategy use'. Concepts such as these are notoriously difficult to define, let alone measure (see for an 
attempt to measure autonomy Lai 2001). It is therefore often not possible to evaluate advisory services on the basis of clear guidelines and outcomes. Also, students come with their own expectations and ideas of self-study, autonomous learning, the teacher's role in this, and other aspects of the learning process, adding another variable (Bartle 2001, Pemberton \& Toogood 2001, Reinders \& Cotterall 2000, Reinders 2004b).

Pemberton \& Toogood (ibidem) specifically investigated this last point by looking at learner and advisor expectations using a number of instruments including recordings of advisory sessions and interviews. They found that learners and advisors had very different assumptions about the purpose of the sessions and expectations of their outcomes. These mismatches sometimes surfaced during the sessions or became apparent from the analysis of the recordings. The authors recommend such analyses as a check to avoid mismatches in subsequent sessions. Analyses of advisory sessions were also conducted by Crabbe, Hoffmann \& Cotterall (2001) and these showed a mismatch between learners' long-term and short-term language learning goals. They argue for the investigation of language learning beliefs as part of the advisory session to highlight such mismatches for the learner.

Jamieson reported three case studies, including one of a Chinese EFL student and showed that "gradual changes in the way students approach the learning process may be achieved" (2002: p. 53) although little elaboration was reported on how this might be done. One outcome from the analyses was the opportunities provided for reflection by the advisers, such as a realisation that there were missed opportunities to ask open questions and "a discrepancy between what one thinks has been said and what was said in reality" (p. 60). Cleary, there is a need for more in-depth investigations of advisory sessions and what happens in them, and the above research has shown that such research can be fruitful.

\section{The study}


An estimated $30 \%$ of the students at the university where this study took place have English as a second language. Many of them have difficulties in their studies due to the language which often results in lower grades or even failed courses. The University offers various types of support to these students. One of these is a Self-Access Centre (SAC). The SAC provides an Electronic Learning Environment (http://www.elsac.auckland.ac.nz) that gives students access to (electronic) language learning resources and supports self-directed learning. When there is sufficient staffing these facilities are complemented by language advisors providing counselling sessions. In 2002 and 2003 the Self-Access Centre successfully tendered for government funding to set up a more structured programme. Students in this programme met weekly with an advisor for a period of three months. The meetings were semi-structured and covered a needs analysis, the development of a learning plan, strategy instruction, monitoring of self-study and feedback. An important goal of the programme was to encourage students to develop skills for self-directed learning so that in future they would be able to further improve their language by themselves.

There had been a feeling among the advisors working on the programme that the sessions were not always an efficient use of staff and student time and that sometimes it took a long time before a clear idea emerged of a student's needs and before a relevant study plan could be worked out, if that happened at all. The present study was an attempt to document the process through which advisor and student come to an agreed set of needs.

For the first part of the study three initial sessions between an adviser and a student were recorded. The first of these had the broad aim of analysing needs and setting goals. The adviser was a staff member in the ELSAC with many years experience as a teacher. At the beginning of the programme she was trained by the SAC director and was given additional support by a colleague in an academic department with expertise in teacher training. Together they conducted the present study. The student was a mature student taking a graduate course in business. He had already worked for some years in different countries. 
It was decided to describe the exchanges functionally in non-technical terms but to keep an eye on lists proposed in counselling literature as well (e.g. Kelly 1996, reported in Jamieson 2002). The researchers then continued with their separate analyses and met again once the whole transcript was complete. This process was repeated in the second phase of the study which involved a session with a different student.

\section{Results}

\section{Student A, Session 1}

\section{Analysing the need}

The 30 minute session started by identifying the course tasks the student had to complete. These were:

Business reports

The context, the arguments

Academic writing

Assignments (including essays)

Next the conversation turned to the students' difficulties with these tasks. Initially he identified his main difficulty as cohesion, saying he was "weak in links" and wrote items "point by point". Early in the interview this discussion turned to his conversational language, when he made a comparison between this weakness in his writing and his spoken language. "Even when I talk, friends told me that I am jumping from here to there." Although this reflection on his spoken English had started as an aside to make a parallel with his writing (Maybe I'm not concentrating... I suddenly cut in), he actually expanded on his oral discourse competence problem for several minutes. He was aware of this change in focus, saying, after some time "Actually it should be writing and speaking. Conversation." The advisor them attempted a summary of the problems the student had mentioned: 
A: OK then. Writing, speaking and a logical organisation of ideas.... And your writing of business reports. Are these the main things?

The student repeated the point about needing to do all this "in an academic way, in a business way up to the level, to the level like graduated." There was then some clarification of whether he was wanting to work at his needs for the present, university context or for his professional work.

At this point in the discussion there was considerable negotiation about the focus of the advice the student wanted. The advisor asked

A: You are trying to write a thesis now, is that the preparation that you would like to do now, right?

He did not actually confirm this.

S: what I would like to say is I want to write to my peers, to my lecturers in a graduated level.

It is unclear at this point whether the advisor and the student shared the same goals and whether the suggested summary reflected the students' needs and concerns.

\section{Narrowing down the focus}

A second phase of the interview started when the adviser said:

A: ... we've found that a good thing for people is to actually be very specific about what you are going to do within the next week before I meet you again. So, out of all these things we have talked about, which do you think is the most important thing you would like to do? 
At this point the student raised a completely new and quite specific topic: the fact that on the telephone people had trouble understanding when he spelled out his name. He called this 'intonation', the adviser labelled it 'pronunciation' and then the student said:

S: Actually it's not a pronunciation, but fluent, fluent topic. Because pronunciation is for each word. I can pronounce it well. I think so.

The next few minutes were spent discussing the student's problems with spoken English. They agreed that the student would like to work on his spoken English through the week, but then when the advisor asked whether there was anything else, he introduced a problem with listening.

S: When I am watching TV very often I cannot get a main idea of TV although I feel that I can understand every word of it.

Not surprisingly, given the initial mention of the university tasks, the advisor reintroduced the topic of writing.

\section{A: “... your writing. Doesn't it matter?"}

S: " Writing is also one of my main ideas. [and, after prompting] ... to understand main ideas of others and to present my own ideas also."

As is clear from the above the advisor is having considerable difficulty to pin down the student's main concerns. The number of different difficulties the student presented made it hard to prioritise or to come to some sort of conclusion from which the two could start working together. The student on the other hand may have felt that by expressing all his 
doubts he was being honest and that it would be the best way for the advisor to really understand his needs.

\section{Planning some action}

The advisor suggested a number of specific actions which the student could take during the week: borrow a CDrom, talk with native speakers, join a conversation group, have a one-toone conversation with the advisor and access a particular website.

The CDrom records the speaker's own language and allows him to compare it with a native speaker's. His response to this was enthusiastic but he immediately added a completely fresh need.

S: "Also I feel that maybe we can have some, like reading newspapers. Just a certain paragraph. After, we can discuss it. I think that this is also good way to..."

The adviser acknowledged this but returned first to the point of his oral English with a second suggestion.

A: "Do you have an opportunity to have a talk with native speakers?"

This led to a third suggestion that he might like to join a conversation group at the SAC.

Her fourth suggestion was to meet with her once a week. This was followed by the student returning to his recent newspaper idea.

A: "Perhaps maybe one of the things that you would like to do when you see me is to prepare something, like read a newspaper, come and talk to me about it." 
Next there was the website suggestion. The adviser listed a number of uses of this which related to more than one of his stated needs. One aspect of this was that he could learn reading strategies. This was followed by a brief explanation by the advisor of various reading strategies.

The adviser then recommended two books for writing and listening for the student to work on by himself.

\section{Concluding the session.}

The final few minutes of the session included some motivational advice "don't feel pressured", some organisational exchanges about the days the adviser would be available, her email contact and the details of how to sign up for the SAC.

\section{Student A, Session 2}

Session 2 was much shorter, lasting only 12 minutes.

\section{The report back}

Session 2 started with reports by the student of what he had done and not done towards last week's intentions. The advisor elicited this by recalling that “... you wanted to work on pronunciation, listening to main ideas, presenting main ideas". First the student reported that he had written a report on a topic that had been prominent in the newspapers. He explained the stages he had been through to write the report. The advisor then offered comments based both on the writing process reported by the student and on his finished product.

He then mentioned what he had done about his listening. He had chosen to listen to a computer programme with speeches from Bill Clinton and Bill Gates. The advisor asked questions about his purpose for doing this and whether he found it helpful. The student said he found it useful and also found his performance on the accompanying exercises to be 
lacking. There was no further discussion of the difficulties he had encountered or the reasons for them.

\section{Self analysis}

At this point there was quite a long discussion which revisited his problems from week 1 . These included details such as the point mentioned a week ago that when he spelled out his name nobody could understand his pronunciation of the letters. People also had difficulty understanding his speech in general. He diagnosed three causes of this problem. One was the differences between New Zealand speech and the British English he said he had learned in Hong Kong. The other two related to his own speech: his intonation and what he described as his lack of logic. ("Sometimes I express it in an illogical way.")

His strategies for improving his English in general were to listen to the car radio for topics that interested him, namely the news, history and economics. With some prompting from the advisor he agreed to attempt a more active approach than the passive type of listening he had engaged in and focus for example on one particular sound or specific expressions.

\section{Student A, Session 3}

\section{Discussion of the previous week's work}

The session started with the advisor giving specific feedback on the report the student had written over the previous week. The student took a large part in this, thanks to the advisor's prompting. This shows in an examination of the ratio of student to advisor talk which had increased compared with the first two sessions. In the middle of this, and arising over the choice of a particular word in the report, there was a discussion on cross-cultural communication, initiated by the student.

\section{Plans for the next week's work}


The last few minutes of the session were taken up with planning for the following week's work. At this point the student returned to the topic which had dominated the first part of Session 1.

A: Ok. What do you want to do this time? Do you want to write more?

S: I want work on cohesion.

The advisor asked if he wanted also to work on his conversational English but he answered "just a cohesion". She prompted again in relation to his examination a month later. ("Does it cause any problems?). His answer was a mixture of yes and no. It turned out that "When I have to answer the questions ... not all of points I understood." In summary his plan for the coming week was "I will read something and we can talk about it."

\section{The advisor's reflection.}

The next stage in the research was to obtain the original advisor's reflections on the sessions and the interaction between herself and the student. She comments:

Reading through the analysis of my advisory sessions with this particular learner I am reminded of Pennycook's (1999: 343) view of a 'critical approach that claims only to emancipate people through a greater awareness of their conditions'. It is '.. doomed to failure'. Obviously, merely isolating language problems, albeit vital to the advisory process, is in itself hardly helping people to learn. I can now suggest the following advice to myself and others about the advising role:

- Having gathered some information on the learner's perceived needs, focus on one language-related problem at a time. However much the learner wants to diverge, stay with that problem. 
- Establish the 'real' problem and explore ways to address it - look both at what the learner can contribute and suggestions I have from my own experience and the available resources. If I can't contribute to a particular area, be honest and tell the learner. Do some homework and talk about it at the next session.

- Ask the learner to choose an option or options to apply to the problem area before the next meeting. Strongly recommend that the learner try a particular technique or adopt a particular approach if they don't want to commit to anything specific.

- Record this plan of action. Give a copy to the learner and keep one for myself.

- Only move on to another problem if there is time.

- At the next meeting, ask the learner to report on the action they took. Give specific feedback, affirming any progress and clearly highlighting areas for further attention. Explore these with the learner. Record this information as an account of the problemsolving process - for the learner and for myself.

As with every teaching and learning situation, language advising is context-specific; each learner and every session creates a unique environment. The advice I give myself applies to the context I was part of with this learner although I believe the overall process can be applied to most advisory situations. I have learnt through hearing what I actually said in these sessions that it is all too easy, supposedly in the interests of promoting 'learner autonomy' to let the learner be rather too directive and offer so little myself. I suggest that, if the learner is not channelled into focusing on one area at a time, the session may spin off in numerous directions where virtually nothing is achieved. Sometimes, then, there is a place for a more assertive advisory approach - to keep the learner focused on specific areas, offer concrete tasks for them to engage in and then give honest feedback. I believe autonomous learning needs to be supported learning - and support that offers something. Sometimes this 'something' may look anti-autonomous. 


\section{Student B, Session 1}

With this next student the advisor took a fresh approach. Building on her experiences and putting into practice some of her own recommendations, several months after the session reported on above she worked on a similar programme and recorded a meeting with a female third-year undergraduate. The transcription of this session reveals a number of differences as the following examples show. The full transcript is attached as Appendix A.

The student's opening question suggested that she was looking for direction.

S: What are we going to talk about?

In this she was typical of learners who are accustomed to teacher-directed learning. However, the advisor needed to be given a general direction.
A: What would you like to...
S: I want to think about it
A: OK

This is followed by a gap of 12 seconds followed by the participant coming up with a fairly specific need:

I think I want talk about presentation skills . because we've got a lot of presentations in the third year. for this semester we've got six mark for the presentation of the case study regarding to the Accounting (...)

This illustrates the need for an advisor to leave time for reflection. 
With minimal prompting from the adviser, this student was able to produce quite specific details of her academic programme needs. The adviser then reworded these for confirmation and there was an exchange that elicited more details. The student's learning strategy (noting the requirements when other students do their presentation) is commended. This is probably important because some students have good learning strategies which they don't recognise as such. In fact he may have seen this as a default mode.

Later during the interview the adviser has established some cognitive, skill-based and affective needs. The latter is attended to first, when the student is reminded of what she can already do. At this point the adviser provides direct input, posed in the form of a question, which allows the student to make a decision about whether or not it seems like a good idea.

For her second suggestion the adviser uses the tactic of elicitation rather than telling. This works. The student is able to recall three strategies for active listening: looking at the speaker, nodding, verifying the question. This pattern continues for several moves. The adviser continues her policy of being more directive and yet eliciting rather than telling. The result is that the student practises actual words he could use.

Eliciting is not the only means of learning. The next point comes by the advisor modelling a response which the student could use later. Sure enough, he makes a note of the example.

This brief description of some of the actions taken by the advisor shows a balancing act between being directive, in the sense of being in control of the interaction, and being encouraging to allow for the student to formulate her own problems and solutions. The transcript shows the advisor providing examples and suggestions in response to these. Although the settings of the sessions reported on in this article differed in a number of respects, with the second student being noticeably less divergent in her talking, we do 
believe that the second transcript clearly shows improvement at a number of levels over the first one(s).

\section{Discussion}

Several points emerged from the analyses and the advisor's reflections. With regards to the development of independent learning skills and the fostering of autonomy in the first sessions the advisor's language could be described as rather non-directive. She gave the student ample opportunity to speak about his language learning difficulties through fairly unstructured sessions with plenty of room for the student to take up topics he felt were important. The advisor's language was suggestive rather than directive, both at the level of managing the topics and at the level of recommending suitable action.

The effect of this was that actual advice was minimal, and not very firm either in its content or methods of application. Few specific tasks were set or recommendations made and no learning plan was construed.

The absence of a directive approach also showed in the lack of feedback to the student. None of the actual feedback given was negative. There are of course good reasons for this but even in session 2 when the student indicates that his scores on a programme for listening skills were rather low, no recommendations are made for improvement. This lack of guidance also shows in the third session where advisor and student discuss a piece of writing the student has produced. Very few problems with the text were identified and discussed.

Is this approach positive or is it negative? The sessions resulted in the student talking about, and hopefully between the sessions thinking about, his language learning in a free exchange of ideas. He apparently felt at ease with the advisor and without this initial feeling of trust perhaps the subsequent sessions would not have taken place at all. On the other hand, the 
lack of structure could have [did?] resulted in less actual advice being given and monitoring taking place. In contrast, in the session with the second student advice was given and included examples, practical recommendations and models of language use. This still provided the student with an opportunity to have her say and draw on previous experiences and knowledge, but the shape of the session was much more structured and coherent. Perhaps the two main conclusions from this paper have to be phrased as questions rather than assertions:

To what extent should an advisor be directive in helping a student? To what extent should an adviser be reining a student back on task?

For the advisor, the answers to these questions were 'more directive than in the present case', and 'to a much greater extent than in the present case' for the sessions with the first student. The advisor says about this: "Until I saw the transcript of my sessions with the first student I hadn't realised that my wish to encourage autonomy led to a situation where I was actually not playing the role of advisor, so much as of a kind friend. That realisation led to adjusting my style as shown in the second interview." The session with the second student was characterised by greater direction and more focus and seemed to have worked better in the context of the programme. For other advisors, working in different contexts, this may be different. The study shows the importance of reflection and discussion with colleagues in any teaching or support situation.

\section{References}

Bartle, J. 2001. Perceptions of the role and functions of the language advisor. In M. Mozzon-McPherson, and R. Vismans (eds). Beyond language teaching towards language advising. London: Cilt, 84-91. 
Crabbe, D., A. Hoffmann, and S. Cotterall, S. 2001. Examining the discourse of learner advisory sessions. AILA review, 15, 2-15.

Fu, Gail S. 1999. Guidelines for productive language counselling: tools for implementing autonomy. In S. Cotterall \& D. Crabbe (eds.) Learner Autonomy in Language Learning: Defining the Field and Effecting Change. Frankfurt am Main: Lang, 107-111.

Gieve, S. (1999). What Makes Thinking Critical? What Makes for Critical Thinking? Discourse Analysis of Episodes in Teacher Education. Theory in Language Teacher Education. H. Trappes-Lomax and I. McGrath. London, Longman: 156-166.

Hurd, S. 2001. Managing and supporting language learners in open and distance learning environments. In M. Mozzon-McPherson, and R. Vismans (eds). Beyond language teaching towards language advising. London: Cilt, 135-148.

Jamieson, A. 2002 The adviser at work. In: Mozzon-McPherson, M. and Vismans, R. (Eds.) Beyond language teaching towards language advising London: CILT (p53 - 65).

Lai, J. 2001. Towards an analytic approach to assessing learner autonomy. AILA review, $15,34-44$

Makin, L. 1994. Learner telesupport: language advising by e-mail. In E. Esch. Self-Access and the Adult Language Learner. London: Cilt, 83-96.

Mozzon-McPherson, M. 2001. Language advising: towards a new discursive world. In M. Mozzon-McPherson and R. Vismans (eds). Beyond language teaching towards language advising. London: Cilt, 7-22. 
Pemberton, R. and S. Toogood. 2001. Expectations and assumptions in a self-directed language-learning programme. In M. Mozzon-McPherson and R. Vismans (eds). Beyond language teaching towards language advising. London: Cilt, 66-83.

Pennycook, A. (1999). Introduction: Critical Approaches to TESOL. TESOL Quarterly, 33(3), 329-348.

Reinders, H. and S. Cotterall. 2001. Language learners learning independently : how autonomous are they? TTWiA, 65, 85-97.

Reinders, H. (2002). Supporting independent learning. Paper presented at the $13^{\text {th }}$ World Congress of Applied Linguistics (AILA 2002 Singapore), Singapore.

Reinders, H. (2004a). Supporting self-directed learning through an electronic learning environment. In Lamb, T. \& Reinders, H. Supporting Self-Directed Language Learning, (forthcoming). Frankfurt am Main: Peter Lang.

Reinders, H. (2004b). University counselling; is it useful? In: Fostering partnership in language teaching and learning, (forthcoming). Hong Kong: University of Hong Kong.

Voller, P., E. Martyn, and V. Pickard. 1999. One-to-one counselling for autonomous learning in a self-access centre: final report on an action learning project. In: S. Cotterall and D.Crabbe. Learner Autonomy in Language Learning: Defining the Field and Effecting Change. Frankfurt am Main: Lang, 111-128.

\section{Appendix A: Transcription}

[transcription conventions:

- Single . in speech indicates short pause of < one second

- Each further. indicates approximately one further second of pause 
(thus ... indicates three second pause)

- (?) indicates unclear speech impossible to transcribe

- (...) indicates section omitted from transcript in the extract] (Gieve, 1999).

$[\mathrm{A}=$ the adviser, $\mathrm{S}=$ the student $]$

S: What are we going to talk about?

A: What would you like to...

S: I want to think about it

A: OK

S: Yeah, I think I want talk about presentation skills . because we've got a lot of presentations in the third year. for this semester we've got six mark for the presentation of the case study regarding to the Accounting (...)

A: Mhm

S: The lecturer gave us along article

A: $M h m$

S: It's about 18 pages . a research article . we have first summarise them

A: $M h m$

S: and then go for Powerpoint and .. print . but it is a group work so it's four peoples in a group

A: Mhm

S: And we got 25 minutes to present these articles to the class and our purpose is related to theory we already studied

A: Mhm

S: So I just think maybe we still lack of presentation skill

A: OK

S: 'Cos I think the body language is important. yeah. and you must make a clear

A: $M h m$ idea to the audience (?) We also got four mark for ask questions

S: It mean every student must ask questions in order to get these four mark . it mean we face a lot of questions!

A: Ahaa

S: And one important skill is handling the questions (?) but I think it is important skill

A: OK. so let me get this right . you're presenting and people who you're presenting to are going to be asking you questions about this presentation . and they get marks for asking questions

S: Yes, yes.

(...)

A: So what you're saying is, one of the skills you need is to know how to handle the questions

S: Yes

A: Aha. So have you done this already? Have you had a trial?

S: No

A: But what are you imagining it might be like?

S: I have no idea . because er luckily we are not the first group to present . we only . we got er four lectures . total eight hour

A: Mhm

S: I mean, one week is two lecture . four teams one week and we are the second week

A: Mhm

S: So maybe we still can learn from other teams

A: Aha . that's strategic

S: But I'm still nervous about that because. you know, when I do the tutorials [she's a tutor for a first year paper] I'm in a small room and just a close relationship . but the lecture room is a big... oh! 
A: So you have to do this in front of everybody, the whole group

S: Yeah . the group in front of the class and the whole class listen to you

A: Ah. how many people?

S: Not so much. maybe in total 40

A: OK but still

S: But the room is big

A: Yes

S: And I think, oh it's different

A: It feels different

S: Yes. I still remember room 9 when I was in Mandarin 291 and we do a presentation and we study (?) skill . but maybe I forgot . like the body

but at the moment it is nervous for me

A: Mhm . alright . supposing you're giving a presentation and somebody's asking

language ..

a question . what do you think may be a good way to handle that?

$S$ : It depend on the question . I think if the question only regarding what we already

A: $M m$ study I'm not afraid because I think I know all the things

S: about our theory . but if out of this course I think I may not be able to handle it

A: When you say 'handle' what do you actually mean?

$S$ : I mean answer this question

A: OK. What are the guidelines? Because there are strategies to use here.

S: No . no guidelines

A: Can you invite the participation of other people to help you answer the question?

S: Yeah. Maybe this is a strategy for me. yeah, because the lecturer only give us the guideline for the whole mark allocated . and one is the ability to handle the question . so it's not show which way you can... you can ask a student

A: OK. so supposing you get somebody asking you a question . what are you doing while that person is asking the question?

S: Listening!

A: Absolutely . what's your body language going to be?

S: (?) I don't think about it . I think just listen

A: Mhm . how do you show that you're listening?

S: Mmm that's interesting ... look at him

A: I think so

S: and er when he's asking the question I just nod my head and if I don't hear ask him to repeat his question . ask him if it's this way (?) what's the question really mean about

A: OK that's a good point . how are you going to do that in a way that isn't going to threaten that person... What would you do here? You're listening

S: Mhm . yes

A: You're trying to understand

S: Yes

A: What happens if you don't quite understand the question?

S: Yeah . l'll just ask again

A: How will you do that? What are the words that you may ask?

S: OK . normally I think I just repeat the question in the way I understand and ask them 'Is that right?' 'Is that your question?' Ask about this kind of question otherwise if I didn't hear very clearly I just ask him to repeat the question . 'Could you say that question again?'

A: OK. Let's be really specific. Supposing somebody asks the question and you don't hear everything. What are the actual words that you might say?

S: Maybe I just say 'Could you say the question again? I'm not quite catch you'.

A: OK you could. Let's think about some other ways you could do it. Can you ask

me any question at all . it doesn't matter what it is. 
S: So. Anything. Um . What subject do you like when you at university studying . what subject do you most like to study?

A: Would you mind repeating that? I didn't quite catch it all

S: Oh! OK [writes it down]

(?)

S: We must handle question . we can handle question by one person. It mean the team member must answer some questions . we have divided our tasks equally (?)

but because the way we have divided our part maybe the question is related to each one's part . I don't know. I have no idea about how to handle question in group situation A: This could be a topic to talk about in your group. Have you got directions about how to organise this particular presentation - from your lecturer?

S: Ah, no . we only from the group and we got the topic and (?) we organise ourselves presentation (...) The problem is because students must keen to ask questions

A: These are two things you could do . what happens if you get lots of people asking questions at once? What are you going to do?

S: Just er . oh . 'I only can handle question one to one' maybe . yeah. I just pick up one

A: Alright . you could say things like 'Right, let's hear this question'.

S: Yes

A: And look somebody in the eye directly . you can use body language to say [indicates invitation to present the question] If you do this [indicates] it says 'Please be quiet and let's listen this person'.

S: Yes . that's good

A: So, 'Let's hear this question first'

S: Yes

A: Supposing you can answer the question . what sort of language will you use? What sort of approach might you take?

S: You mean when I answer the question?

A: $M m m$

S: I think .. I just answer them . just explain them like if they're not clear the idea the hypothesis of this test, I just repeat the hypothesis and explain why the hypothesis don't like this way

A: Mmm . sometimes it's good not to be too direct . this is... you know, hedge alittle bit.

You know about hedging? 'It could be this', 'this is a possibility', 'maybe...'

S: maybe . yes because all our presentation is regarding the research study so I think mainly it's just possible because it's an average one not exactly this one or that one

A: So you might get someone saying to you 'Surely it's like this...' from the floor

S: Oh yes, yes

A: How would you handle that?

S: Could you please say that again?

A: Suppose somebody in the question time wants to challenge you and say 'Well I don't agree. It's like this...' What might you say?

S: Um .. because related to our presentation topic it's mainly about a research study so it means this not give you the actual theory about it. it's just observation of the study so I can't say you right or not

A: And you could say some thing like 'That could be correct' or 'That's a possibility, however we are trying to establish one perspective' or something like this. So you're not excluding that person

S: Yes, yes.

A: I think the thing is not to get into conflict over your question answering . I think you can handle it very well

S: Oh, you know I am always handling! . you know in my tutorials they normally ask questions... because if this question is in my later slide I will say 'Oh, thank god, I will talk about that later after the (?)

A: Good . that's a very good strategy

S: Yes . but if only (?) 
A: Supposing you get a question but you know there's somebody in your group who could answer it more fully because this isn't particularly your area . what could you do?

S: ... I just go . pass the question to my group member

A: Or you could speak directly this member and say (...) 'Joe I know you know about this, S: Yes could you add anything here?'

A: Would you like to answer this question? This person may say 'No, no, you do it' . Fine . but this is a strategy - have included somebody else. 'Cos you're not claiming to know everything

S: Yeah, I think, yeah your suggestion is really a good thing . it's also difficult

A: But don't get phased either . the worst thing to do is panic

S: Yes

A: So, take your time. if you need a moment to think, take that moment

S: Yeah!

(...)

A; Just relax and keep an alert mind I think . is very important

And another thing to remember when answering questions ... is to actually address the question rather than going off on a tangent . there's nothing worse than if you

S: Yes want to know something but the person doesn't answer your question

A: they talk about something else . so stick to what you've been asked . if you can answer it, great . if you can't, pass it to your team member. or what else could you do? If you really are stuck what would you say?

S: I think it is out of our study scope... maybe . oh I don't know

A: Why not say something like 'That's a very interesting question, however I'm not sure I can answer that at the moment but it is something I could look at in the future' or 'It's a really interesting question but actually it's beyond the scope of our research', just like you said

S: Yes, that's good.

A: So I think it's good to think through what could happen . scenarios

S: Yes

A: possibilities . 'What would I do if...?' And l've taken you through some . if you can't hear,

S: Mhm if you don't understand, if you don't know

A: And just be a little bit prepared for that . think about the actual language that you may be able to use . remembering to keep your language not too direct, and be polite, keep

S: Yes! smiling, you win people by your personality which you can do

A: I mean it may be a serious issue, but it's OK to relax, it's alright

S: Yes (laughs)

A: these people . they're not going to beat you up or anything (laughter) and you'll develop your own way of presenting but it's a massive undertaking actually . there's a second level paper in our department and it teaches presentations (...) And there's also some very good information at the ELSAC, where you've been already, on presentations

S: Yes, yes

A: on this very thing . what you're saying about body language . all those things are covered and I think they also run a workshop on presentations

S: Yeah I know that I want take it but no time take it .

A: So we can do a little bit here in a limited time

S: Yes . I will look at some books and see... yeah because we always have a study in Management (...) the skills for the presentation

A: Oh, so you have covered it somewhere

S: Yeah, but it's just no practical

A: Exactly . are you going to practice in your group? 
S: Yes. Yeah, I think one problem is our group got four people. three girls include I and we all the tutor . it mean I think... but other is a boy and just he just normally shy to speak up

A: Yes, yes.

S: So I think this maybe a problem when we present because... I just think about it

A: That you three are going to do OK and he might be weak?

S: Yes

A: What do you think you could do between now and your presentation time? What practical step might you be able to take to develop as a group? Any ideas?

S: I think because we just think we should practice more before the presentation I think we just encourage him a lot

A: What you could do is take along a tape recorder

S: $M m m$ yes

A: Tape the whole thing, play it back together

S: It's a good idea

A: And let each person hear what's going on . you have to be careful though, let it be a positive feedback time. and encourage... you could set the tone actually and be the example and you listen to yourself and say 'Oh, I could have done this', 'I did that pretty well, that was great' or 'I can't hear what I was saying' . and this might help him

S: Yes to do the same sort of thing

A: And then do it again . better still if you could get a video of yourselves but I don't know how practical that is

S: I've got a video in my home

A: And a camera?

S: Yeah we got a camera

A: Well set up the camera . it doesn't matter how bad the...

S: Yes, yeah . I think that's a very good idea . I think it's very useful when you see actually see what are you doing there

A: Absolutely

S: and you can... oh, it's not a good habit and you can just do

A: and say 'How can I improve?' and invite the others ' now, how can I do better here?' . invite their input and I think you might find that the guy will actually develop in this

S: Yes way

A: How much time have you got between now and the presentation?

S: Our presentation is the $1^{\text {st }}$ of June

A: OK so you've got a couple of weeks

S: Yeah, but badly we've still got at that day we've still got another test (24.5) (...) but I think we'll do very well

A: Great! In this course that they run in our department for presentations this is a very important aspect . that they work together as a group and prepare something and it's videoed . they have to record themselves and then analyse their own presentation

S: Yeah! This is a good idea. Yeah I can do it because l've got a video, yeah

A: Yes.

Let's just go through this (some diagnostic feedback) just a couple of minutes

S: Yes

A: Alright 'regarding to the lecture 392'. Is there anything you want to change?

S: Aaah . to the paper maybe

A: You don't need this

S: Oh, regarding the lecture, yes

A: 'We have first summarised them'

S: Oh, we have first summarised them already, maybe

A: Oh, we have summarised them already? Or 'First of all we have to summarise them'

S: Oh yeah 
A: I'm not sure . I didn't know what you were meaning here

S: Yeah. What I meaning is we... there several parts . first part is give a summary of these three points

A: Ah . ok this created some problem for me because I didn't understand . it's just the

S: Mhm yeah

A: 'Four peoples in a group'

S: Four peoples . I think it... the group have four peoples

A: What's happening here? [points to the first two words]

S: Four peoples .. ah, no, no, four people

A: Ah, ok

S: Yes

A: 'total eight hour' what was that?

S: 'total eight hour'?

A: you were talking about I think a length of time . in total it was eight...

S: Oh I say ' the total of whole the groups in the presentation is add up is eight hour'

A: Oh so you want an article . 'a total of eight hours'

S: of

A: hours

S: hours

A: It's all these little things here

S: Yes, mhm

A: Please don't get discouraged if I do this

S: Yeah, yeah it's fine if just correct my problem . I'm happy

A: You're easy to understand, however you could improve by just paying attention here . so you may want to attend to these - these plurals even - when you add them and

S: Yes, yes when you don't . it's a difficult one but it's something you could look at

A: What's this word?

S: difficult

A: Ah, difficult

S: When you're speaking quickly l'm going 'What's that word?'

A: Yeah! (28.5) 